\title{
A Review on the Effectiveness of Canadian and American Mental Health Courts
}

\author{
David Tyler Dunford, ${ }^{1,2}$ Andrew Haag ${ }^{3,4}$
}

${ }^{1}$ Department of Sociology, University of Alberta, Alberta Health Services; ${ }^{2}$ Alberta Health Services, Mental Health and Addictions, Edmonton Alberta; ${ }^{3}$ Department of Psychiatry, University of Alberta; ${ }^{4}$ Alberta Health Services, Mental Health and Addictions

\begin{abstract}
Objective: This systematic review synthesizes mental health court (MHC) research across the United States and Canada. This study reviews and compares the operations and practices of MHCs across both countries, as well as their recidivism rates.
\end{abstract}

Methods: We gathered from existing literature to present common MHC practices used across the United States. However, in response to the lack of literature about Canadian day-to-day practices, we developed a questionnaire and contacted every Canadian MHC. In total, we contacted 36 Canadian MHCs, and 19 courts filled out a questionnaire. With respect to recidivism rates, we conducted a comprehensive literature search in February and March 2019 in PsycINFO, Google Scholar, Web of Science, and National Criminal Justice Reference Service Abstracts using the keywords mental health court, therapeutic justice, serious mental illness, mentally ill offenders, mental health diversion and problem-solving courts.

Results: Canadian and American MHCs have similar practices. However, American MHC's have more robust screening measures and typically admit more participants with schizophrenia, bipolar disorder, and major depressive disorder into their programs compared to Canadian MHCs. MHC participants in both countries typically had lower recidivism rates compared to regular docket court participants.

Conclusions: MHC research should inform public policy. Additional research should move in the direction of discovering the predictors for why MHCs reduce recidivism.

Key words: meta-analysis, mental health courts, Canada, United States, practices, recidivism

\section{Introduction}

There has been a steady deterioration of services for the mentally ill across North America [1-3]. For the past several decades, the criminal justice system (CJS) has emerged as the safety net for those with mental illnesses. Criminal justice data from across Canada and the United States have documented the alarming overrepresentation of prisoners with mental health problems or mental illness diagnoses, with the U.S. Department of
Justice reporting that $24 \%$ of state prisoners and $14 \%$ of federal prisoners had a mental health problem within the previous 12 months [4]. In Canada, the Office of the Correctional Investigator reported that $13 \%$ and $29 \%$ of male and female federal prisoners had a mental health diagnosis, with both rates of men and women doubling between 1997 and 2008 [5].

Beginning in the 1980s and 1990s, various actors (judges, lawyers, and other criminal 
justice practitioners) began criticizing the overrepresentation of offenders with mental illnesses (and acute addictions) and the failure of several government departments, agencies, and initiatives to adequately address their complex risks and needs $[6,7]$. As a result, many states and provinces established community-based therapeutic interventions and treatment options $[8,9]$. In this context, mental health courts (MHC) arose as an alternative to traditional courts. MHCs focus on providing therapeutic, recovery interventions, and predominately operate according to the following three main assumptions and goals:

1. MHCs can decrease the recidivism rates of mentally ill patients,

2. MHCs can address and improve the quality of life and health outcomes of mentally ill offenders, and

3. MHCs can reduce regular court and other criminal justice costs.

There is a need to synthesize the recent research on MHCs given the sheer amount of published research and the proliferation of MHCs. In recent years, there have been a series of meta-analyzes and systematic reviews on MHCs to synthesis this research [10-14]. However, these articles have almost exclusively focused on American contexts. Although those articles are undoubtedly insightful and useful, the aim of this article is to add to the literature by comparing Canadian and American MHCs. Specifically, this systematic review:

1. compares and contrasts the designs and practices of Canadian and American MHCs (qualitative differences) and

2. compares and contrasts recidivism rates (quantitative outcomes) of Canadian and American MHCs.

To address the first point, we gathered information from existing research in the United States to analyze the practices of American MHCs. However, due to a lack of existing research on the practices of Canadian MHCs, we developed a questionnaire and contacted MHCs across Canada. To address the second point, we conducted an exhaustive literature search on recidivism rates in several databases.

In this article, we review existing research as well as introduce novel research. We first review existing research in the United States, including the purpose and core structural components of American MHCs. Second, we present our findings on the practices and purposes of Canadian MHCs. Third, we systematically review recidivism rates of MHCs in Canada and the United States. Finally, we discuss future areas of research.

\section{Literature Review: American MHCs}

Two major factors contributed to the creation of $\mathrm{MHCs}$ and other problem-solving courts. First, interest groups across the political spectrum criticized the enormous economic costs associated with mass incarceration in the late 1980s and 1990s [15]. For instance, scholars $[16,17]$ vehemently criticized get-tough-oncrime policies because of the growing criminal justice costs. Second, the term "therapeutic jurisprudence" started to emerge in the criminal justice field at that same time and spread into other social arenas [1,18]. Therapeutic jurisprudence links crime to larger social structures and psychological factors, and aims to improve the well-being of individuals who are involved in the justice system. Broadly speaking, therapeutic jurisprudence provides individuals with a series of services-such as housing, addictions treatment, and psychotherapy - to help reduce their interactions with the CJS. In this context, problem-solving courts were developed across the United States to address increasing prison populations and costs for those with mental illnesses or other specialized needs [19].

The Miami Drug Treatment Court established in 1989 represented the first problem-solving court in the United States. This court addressed the growing recognition that sentencing those with drug addictions did not reduce recidivism [20]. The first MHC emerged in 1997 in Broward County, Florida, to divert offenders with mental illnesses away from the criminal justice system. MHC's have proliferated since 1997, with the Council of State Governments [21] indicating there are now more 
than 300 American MHCs. The United States typically has two different types of MHCs:

1. the first wave of MHCs that predominately target nonviolent offenders charged with misdemeanours, and

2. a second, newer wave of MHCs that target offenders charged with felony crimes [22].

The Council of State Governments represents the foremost educational and funding body for American MHCs. The Council [21] has provided assistance and training to more than $100 \mathrm{MHCs}$ throughout the United States. The Bureau of Justice Statistics and the Council of State Governments [23] established 10 defined, shared elements for all American MHCs to follow. These elements distinguish MHCs from regular courts and include:

1. planning and administration;

2. identifying criteria and a target population;

3. timely participant identification and linkage to services;

4. individualized terms of participation;

5. participant-informed choice;

6. treatment supports and services;

7. confidentially sharing health and legal information among court actors (e.g., lawyers, probation officers, and mental health professionals);

8. court are provided with continuous mental health training and education;

9. monitor if the participants follow their court-mandated conditions; and

10. collecting data on each $\mathrm{MHC}$ to ensure its effectiveness and to ensure community support for the program [24].

MHCs across American and Canadian jurisdictions broadly operate according to one or more of the following purposes:
1. to provide a separate docket court for those who suffer from serious mental illness(es);

2. to decrease the recidivism rates of $\mathrm{MHC}$ participants;

3. to deliver therapeutic, community, or both interventions to improve health outcomes; and

4. to monitor the level of compliance $[12,13]$.

\section{MHC screening}

A study of six American MHCs represents the foremost research on the selection process [25]. There are typically three stages of MHC participant screening: initial screening, assessment eligibility screening, and evaluation screening. During the initial screening, members of the prosecution, judges from other courts, law enforcement officers, defence attorneys, probation officers, and prison staff refer potential participants to MHCs. The district attorney and MHC team determine if the individual's charges, criminal history, and mental illness match the court's eligibility criteria [25]. Potential MHC participants are screened out due to ineligible offence-type. For instance, some MHCs only admit those with misdemeanour offences while others only admit those with felony charges [26].

Those who meet the first stage requirements are referred to a more in-depth review, often conducted by mental health professionals. The mental health team primarily determines whether the potential participant meets the mental disorder criteria and whether their mental disorder played a role in the index offence. Drawing from a meta-analysis of 18 studies [27], the vast majority of individuals ultimately admitted into $\mathrm{MHC}$ have either a schizophrenia, bipolar or major depressive disorder diagnosis (sometimes referred to as the big three). However, other MHC studies also indicate that some courts admit a variety of conditions, including anxiety, developmental disabilities, substance abuse, and personality disorders [28], although these illnesses often co-occur with the big three. If the mental health team determines the individual has met the illness criteria, 
the team then decides "on the client's willingness and ability to comply with treatment conditions" and their criminal history (e.g., history of violent crime) [25]. Those who do not meet these criteria are deemed ineligible for MHC participation.

At the final screening stage, the judge requests the client meet with them to determine final admission into $\mathrm{MHC}$. Although there is some variability, most American MHCs use a combination of these screening phases to determine participant eligibility.

\section{MHC participant demographics}

There are four primary demographic features of MHC participants. First, female participants are overrepresented in MHCs compared to the general prison populations [29]. This being said, there are still more males than females enrolled in MHCs [30]; however, in some jurisdictions, females comprise the majority of MHC participants [31]. Second, a large subset of studies report participants to be typically in their earlyto late-30s. [28,32]. Third, research indicates that there is an overrepresentation of white people and an underrepresentation of Black people, despite a vast overrepresentation of Black people in American prisons [32]. Finally, research indicates that the vast majority of participants enrolled in MHCs have been diagnosed with severe mental illness(es) [33].

\section{Sanctions and rewards}

MHC judges generally provide participants with a series of court conditions, such as attending psychotherapy, taking prescribed medications, abstaining from intoxicants, and weapon prohibitions [34]. MHCs frequently sanction participants for their noncompliance with their conditions and reward them for their compliance. Sanctions and rewards establish the right balance between "the carrot and the stick" to ensure compliance. This carrot-and-stick approach can be particularly effective for MHCs that dismiss the participant's charges when they successfully complete their court conditions [6].

MHCs employ a wide series of sanctions to ensure compliance, including the judge harshly criticizing MHC participants [35], forcing the MHC participant to sit and watch other defendants in the court gallery all day, urinalysis, and increasing the number of probation officer appointments [36]. A study reported that prison was used as a last resort in three of the four MHCs we studied, and that judges used prison as a sanction in $21 \%$ to $34 \%$ of their cases [37]. Alternatively, MHCs also frequently reward participants for complying with court conditions. Common rewards include the judge praising the participant in the courtroom, reducing or eliminating court supervision and appointments with probation officers, and reducing or overturning urinalysis orders [6]. Globally, the use of sanctions and rewards is implemented to assist MHC participants in adhering to treatment and conditions.

\section{Methods}

\section{Canadian MHC practices}

We did not find a qualitative review of Canadian $\mathrm{MHC}$ practices in academic literature. To address this gap, we developed a standardized Excel document with 35 questions and contacted every Canadian courthouse or Canadian Mental Health Association office in every Canadian city with a population of more than 100,000 , excluding Quebec. We did not contact Quebec jurisdictions because we are not fluent in French. Every $\mathrm{MHC}$ that was contacted was asked if they knew of any other MHCs in their province that had a population of less than 100,000 (see Table 1). Surprisingly, we discovered several MHCs in smaller jurisdictions. Port Hawksbury, Nova Scotia (population 3,214), is the smallest jurisdiction with a MHC. Conversely, Calgary, Alberta, is the largest city without an MHC (population 1.33 million). We spoke to representatives from 71 Canadian jurisdictions. Of these, 36 jurisdictions reported they had an $\mathrm{MHC}$, for a total of 47 Canadian MHCs (there are $11 \mathrm{MHCs}$ in Quebec). If a jurisdiction had an $\mathrm{MHC}$, we asked the representative if we could email them a questionnaire to fill out. Nearly every jurisdiction consented and gave us their email. In total, we found that there are $24 \mathrm{MHCs}$ in Ontario, 11 in Quebec, four in Nova Scotia, two in Saskatchewan, and one in each of Alberta, British Columbia, Manitoba, 
Newfoundland and Labrador, New Brunswick, and the Northwest Territories.

We then attempted to communicate with the courts about information that is in the public domain (e.g., Do you have a court? What are the court procedures?). Nineteen Canadian MHCs responded. We collected information on numerous court practices, most notably:

1. basic MHC information and goals,

2. screening and eligibility, and

3. incentives and sanctions that are used in the courts.

\section{Recidividism rates}

Five articles previously conducted a standardized review of recidivism rates for MHCs [10-14]. All these articles reported that MHC participants typically had lower recidivism rates compared to those in regular court. Although these articles are important and noteworthy, this study adds to the literature by providing a review of Canadian MHCs, which has not been done to date.

The lead author conducted a comprehensive literature search in February and March of 2019 in PsycINFO, Google Scholar, Web of Science, and National Criminal Justice Reference Service Abstracts using the keywords mental health court, therapeutic justice, serious mental illness, mentally ill offenders, mental health diversion and problem-solving courts. We looked in the reference sections for additional articles.

Five inclusion criteria included articles that:

1. were published in English;

2. included adult MHCs (as opposed to youth);

3. used recidivism as a dependent variable (e.g., arrests, conviction, or time spent in jail);

4. included an experimental and comparison group (MHC-TAU [treatment as usual]) or a pre-post design between completers and noncompleters; and
Table 1: Canadian mental health courts (e.g., community wellness courts, therapeutic courts), excluding Quebec

\begin{tabular}{|c|c|c|}
\hline City or town & $\begin{array}{r}\text { Population } \\
\text { (2016 figures) }\end{array}$ & $\begin{array}{r}\text { Completed } \\
\text { Questionnaire }\end{array}$ \\
\hline Edmonton, Alba. & 932,550 & Yes \\
\hline Victoria, B.C. & 85,795 & No \\
\hline Winnipeg, Man. & 705,245 & Yes \\
\hline Saint John, N.B. & 67,575 & Yes \\
\hline St. John's, N.L. & 108,860 & Yes \\
\hline Amherst, N.S. & 9,413 & Yes \\
\hline $\begin{array}{l}\text { Dartmouth, N.S. } \\
\text { (includes Halifax) }\end{array}$ & 403,390 & Yes \\
\hline Kentville, N.S. & 6,271 & Yes \\
\hline Port Hawksbury, N.S. & 3,214 & No \\
\hline Bradford/Alliston, Ont. & 28,077 & No \\
\hline Brockville/Leeds, Ont. & 21,854 & No \\
\hline Greater Sudbury, Ont. & 161,530 & Yes \\
\hline Guelph, Ont. & 131,795 & No \\
\hline Halton/Milton, Ont. & 548,435 & Yes \\
\hline Hearst, Ont. & 5,550 & Yes \\
\hline Huron-Perth, Ont. & 59,297 & Yes \\
\hline Kenora, Ont. & 15,096 & Yes \\
\hline Kingston, Ont. & 123,795 & No \\
\hline Kitchener, Ont. & 233,220 & No \\
\hline Lambton/Sarnia, Ont. & 123,399 & No \\
\hline Lindsay, Ont. & 20,354 & No \\
\hline $\begin{array}{l}\text { London/Middlesex, } \\
\text { Ont. }\end{array}$ & 383,825 & Yes \\
\hline Markham, Ont. & 328,965 & Yes \\
\hline Oshawa, Ont. & 159,455 & No \\
\hline Ottawa, Ont. & 934,240 & No \\
\hline Owen Sound, Ont. & 21,341 & No \\
\hline Oxford/Norfolk, Ont. & 110,862 & No \\
\hline Peel, Ont. & $1,382,000$ & No \\
\hline Peterborough, Ont. & 81,035 & Yes \\
\hline Sault Ste. Marie, Ont. & 73,368 & Yes \\
\hline Toronto, Ont. & $2,732,000$ & No \\
\hline Vaughn, Ont. & 306,230 & No \\
\hline Windsor, Ont. & 217,185 & Yes \\
\hline Regina, Sask. & 215,105 & Yes \\
\hline Saskatoon, Sask. & 246,375 & Yes \\
\hline Yellowknife, N.W.T. & 19,569 & No \\
\hline
\end{tabular}


5. were published in a peer-reviewed academic journal.

Articles that analyzed participant's self-reported criminal involvement were excluded because of the unreliability of self-report measures of criminal involvement.

\section{Results}

\section{Canadian MHC practices}

The first Canadian MHC opened in Toronto on May 11, 1998 [1]. The scholarly literature does not outline the number of MHCs across Canada, although the Canadian Human Services and Justice Coordinating Committee [38] reported there were 18 operational courts in Ontario and 11 MHCs in Quebec in 2018 [39].

\section{Basic information and goals of Canadian MHCs}

Of the $19 \mathrm{MHCs}$ that answered the questionnaire, four operated two or three times per week, three courts operated once per week and $12 \mathrm{MHCs}$ operated a few times a month or less. None of the MHCs were functional eight hours a day or more because many of these courts operated in small jurisdictions and did not have large caseloads. However, seven MHCs functioned between five to eight hours per day, six MHCs operated between two to five hours per day, and five MHCs operated between one and two hours per day.

MHCs were asked if they had goals or measures of success and, if so, the MHCs were asked what those measures were. Fifteen of the MHCs stated that they had clearly defined goals or measures of success, with some having multiple goals. Goals included diversion (six courts), improved health outcomes (six courts), reduced recidivism (five courts), and improved well-being (four courts). Although 15 courts had stated goals, only two of them had done a robust analysis of how to measure their court's success $[40,41]$.

\section{Eligibility and screening}

Every Canadian MHC has eligibility criteria (typically several criteria), with some courts having stricter criteria than others. To be eligible for
MHC, 13 MHCs reported that the participant's mental illness must have played a key role in their alleged index or predicate offence, 12 MHCs indicated that their participants had to have a diagnosed serious mental illness, and 10 MHCs stated that the participant must agree to treatment. Some courts were more lenient in their mental illness eligibility: five noted that they would admit participants into their $\mathrm{MHC}$ if there was evidence of a mental illness or mental health issue. Four indicated that they would admit participants who had developmental disabilities or brain injuries, and nine reported that prospective participants must meet all the criteria to be eligible for MHC.

Fourteen MHCs excluded participants based on offence types. The most common excluded offence was homicide (14 MHCs), followed by sexual offences (10 MHCs), and domestic violence (five MHCs). Other excluded offences included serious assaults (two MHCs), driving offences (two MHCs), and offences against children (two MHCs).

All 19 MHCs indicated that both the crown and defence (including duty counsel) referred cases to MHC. Ten courts indicated that judges from other courts referred cases. Other referrals came from the police officers, mental health professionals, and family. Once potential participants were referred to an $\mathrm{MHC}$, the court would then conduct a screening to determine eligibility. Only one court did not have any person devoted to screening potential MHC candidates. The other MHCs had the following people involved with screening:

1. the crown (14 MHCs),

2. mental health professionals (predominately comprised of either one of, or a team of social workers, psychologists, and psychiatrists-13 MHCs),

3. the defence (five MHCs),

4. probation officers (two MHCs), and

5. court support workers (two MHCs).

The crown and mental health professionals collaboratively engaged in screening measures in 
10 MHCs. Three MHCs admitted nearly $100 \%$ of referred cases, $11 \mathrm{MHCs}$ admitted about $75 \%$, and five MHCs admitted about $50 \%$.

\section{Sanctions and rewards}

Thirteen of the MHCs officially offered (multiple) opt-in incentives to encourage participants to participate. Twelve of them offered to stay or withdraw the charges after successful completion of the program, nine offered to reduce the participant's sentences, and two offered to terminate sentences. Three courts informally stated that they typically offered reduced justice outcomes for participating.

Either a probation officer, court support worker, case manager, or a combination of these ensured MHC participants followed their conditions in 12 MHCs. The types of sanctions imposed on participants varied widely. Eight MHCs required participants to attend court more frequently in the case of noncompliance, six removed the participant from the MHC program, four required the participant to sit in the court gallery for a full-day, and two courts forced the participant to engage in community services hours. Finally, seven MHCs used jail as a sanction of last resort.

\section{Recidivism rates}

A total of 87 articles met the initial search parameters. Of the 87 articles, we determined 18 articles ultimately met our search criteria in the United States: 14 studies compared recidivism rates between MHC and TAU participants, and four study designs compared recidivism rates for MHC completers and noncompleters. We both analyzed all 87 articles: 100\% interrater reliability was achieved. Originally we used the same search parameters for both Canadian and American MHCs; however, we expanded the inclusion criteria given that only one article met the criteria [41]. We included four other articles that employees associated with Canadian MHCs recommended to us $[40,42-44]$, which included three Canadian articles that were not published in academic journals, and one that did not have a comparison group.

\section{American studies}

Although most of the American studies matched MHC with TAU participants $(n=14)$, we also reviewed four articles that compared the recidivism rates for participants who completed the MHC program (completers) and participants who either opted out of or were expelled from the program (noncompleters). The MHC-TAU group designs compared the recidivism rates for MHC and TAU participants, whereas the other four studies compared recidivism rates for completers and noncompleters. Nearly all the studies included 12- to 24-month follow-up periods and defined recidivism as a combination of rearrest and booking rates, reconviction rates, time spent in jail, and time spent between arrests. Some of the MHC-TAU-group designs $[37,44]$ differentiated between $\mathrm{MHC}$ completers and noncompleters.

Eleven of the $14 \mathrm{MHC}-\mathrm{TAU}$ designs reported that MHC participants had lower recidivism rates compared to TAU participants, with most of these studies reporting considerably lower recidivism rates (see Table 2 [45-58]). However, when controlling for MHC completers and noncompleters, all three articles that reported MHCs did not reduce recidivism ultimately did report that MHC completers had the lowest recidivism rates, followed by TAU participants and finally noncompleters.

Every MHC-TAU-group design that differentiated between MHC completers and noncompleters [52] indicated that completers had the lowest recidivism rates, followed by TAU participants, and then noncompleters. This difference was most apparent in a study [56] that reported $\mathrm{MHC}$ completers were 3.7 times less likely to reoffend compared to noncompleters. A series of scholars attributed decreased recidivism rates among completers (compared to noncompleters) to be the result of the full treatment or full dosage of MHC [55].

MHC completers had significantly lower recidivism rates (Table 2). For instance, a study [58] indicated that $39.6 \%$ of completers were rearrested in the five years following their 
Table 2: Summary of American MHC research that analyzes recidivism rates

Study

Anestis \& Carbonell, 2014 [45]

Quasi-experimental

Pre-post comparison*

Christy et al., 2005 [46]

Broward County, Florida

Quasi-experimental

Pre-post comparison*

Cosden et al., 2005 [34]

U.S. (location unknown)

Experimental

Pre-post comparison*
Southeastern United States

\section{Findings}

MHC participants had significantly lower rearrest rates $\left(X^{2}=20.89, p>.001\right)$ and longer periods before reoffending $(t=-4.66, p>.001)$ compared to TAU participants in the one-year follow-up.

No significant difference between $\mathrm{MHC}$ and TAU participants (one-year rearrest rate 47 per cent MHC and 56 per cent TAU). These results were not statistically significant $(p<.23)$

Arrest rates one year

\begin{tabular}{cc} 
MHC & TAU \\
\hline 47.00 & 56.54
\end{tabular}

Relatively similar $24-$ month recidivism rates. These results were not statistically significant in terms of number of bookings $(p<.01)$, number of convictions $(p<.05)$ and number of jail days $(p<.05)$.

Mean number of bookings

MHC

TAU

Mean number of convictions

5.33

3.89

Days in jail

1.82

2.04

22.55

Frailing, 2010 [47]

San Francisco, California

Quasi-experimental Pre-post comparison*

Mean number of days in jail pre- and postcourt referral or involvement. The authors did not report if these results were statistically significant

\begin{tabular}{lcc} 
& MHC & TAU \\
\cline { 2 - 3 } One-year prereferral/court resolution & 56.62 & 56.54 \\
One-year postcourt involvement & 11.99 & 134.61 \\
\hline
\end{tabular}

Han \& Redlich, 2015 [48]

San Francisco County and Santa Clara County, California; Hennepin County, Minnesota; and Marion County, Indiana

Pre-post comparison*

Six-months preenrolment

MHC

TAU

Mean number of days in jail for six-months pre- and postcourt involvement. These results were statistically significant $(p<.001)$.

Six-months postenrolment

1.31

1.85

0.45

0.65

Rearrest rates for MHC and TAU participants. The results indicated the difference to be statistically significant $(p<.001)$

District of Columbia

Quasi-experimental

Pre-post comparison*

Two-year rearrest rate

\begin{tabular}{cc} 
HMC & TAU \\
\hline $38 \%$ & $48 \%$
\end{tabular}

Significant reduction in rearrest rates post one year for $\mathrm{MHC}$ participants. The results indicated this difference was statistically significant $(p<.001)$

District of Columbia

Quasi-experimental

Pre-post comparison*

Keator et al., 2013 [51]

San Francisco County and

Santa Clara County, California;

Hennepin County, Minneaspolis

Quasi-experimental

Pre-post comparison*

\begin{tabular}{lcc} 
& HMC & TAU \\
\cline { 2 - 3 } One-year rearrest rate & $27.5 \%$ & $37.7 \%$ \\
MHC participants and TAU participants had similar rearrest rates in the seven to 18 \\
months post program. The authors did not report statistics between the two groups.
\end{tabular}


Table 2: Summary of American MHC research, continued

\section{Study}

Kubiak et al. 2014 [52]

(location unknown)

Quasi-experimental

Pre-post comparison*

\section{Findings}

Mean number of days in jail and state prison for MHC completers, MHC noncompleter and TAU participants for a period of one-year postdischarge. The authors found a statistically significant relationship between $\mathrm{MHC}$ completers and noncompleters and TAU $(p<.001)$ in terms of number of days in jail but not for number of days spent in state prison.

MHC completers MHC noncomplete

TAU

Mean number of 4.73 23.20 49.27 days in jail

Mean number of 5.38

130.00

48.70 days in state prison

Lowder et al., 2016 [53]

St. Paul, Minnesota

Quasi-experimental

Pre-post comparison*

No significant differences between MHC and TAU in terms of incurred charges oneyear postprogram. The results indicated the rearrest rates for $\mathrm{MHC}$ participants were statistically significant $\left(X^{2}=13.50, p=.001\right)$

Arrested

MHC TAU

Any rearrest

$27.5 \%$

$37.3 \%$

Any violent felony rearrest

$8.1 \%$

$9.8 \%$

Significantly reduced recidivism. The authors reported a longer time for new charge $(p<$

McNeil \& Binder, 2007 [28]

San Francisco, California $.0001)$ and longer time for a new violent charge $(p<.0001) \mathrm{f}$ or MHC participants.

Quasi-experimental

Pre-post comparison*

24-month charge rate

MHC

TAU

24-month violent charge rate

\begin{tabular}{cc} 
MHC & TAU \\
\hline $36 \%$ & $61 \%$ \\
$7 \%$ & $15 \%$
\end{tabular}

McNeil et al., 2015 [54]

San Francisco, California

Quasi-experimental

Pre-post comparison*

Violent offences between MHC and TAU participants six months after program admission. The authors did not report if the results were statistically significant.

Moore \& Hiday, 2006 [55]

Rural population in

Southeastern United States

Quasi-experimental

Pre-post comparison*

Steadman et al. 2011 [33]

San Francisco County and

Santa Clara County, California; Hennepin County (Minneapolis), Minnesota; and Marion County, Indianapolis

Quasi-experimental Pre-post comparison*
MHC TAU

12-month act of violence rate

$25 \%$

$42 \%$

Rearrest rates between $\mathrm{MHC}$ and TAU participants 12 months after entry in $\mathrm{MHC}$ and Traditional Criminal Court. The results are statistically significant $(p<.001)$

MHC

TAU

Average number of re-arrests

1.10

2.36

The average number of arrests and days spent in custody between MHC and TAU participants. The results indicated the average days spent behind bars was statistically significant $(p \leq .001)$ but the rearrest rates were not statistically significant $(p<.006)$.

Rearrest rates post-18 months

Average number of days incarcerated pre-18 months

\begin{tabular}{cc} 
MHC & TAU \\
\hline $49 \%$ & $58 \%$ \\
73 & 75 \\
82 & 152
\end{tabular}


Table 2: Summary of American MHC research, continued

\section{Study}

Burns et al. 2013 [31]

County in Northern, Georgia

Pre-post comparison†

Findings

Rearrest rates and mean days spent in jail post program exit two years following court exit. The results indicated the rearrest rates $(p<.001)$ and mean days spent in jail for MHC participants were statistically significant $(p<.001)$.

\begin{tabular}{lccc} 
& MHC & $\begin{array}{c}\text { Voluntary } \\
\text { drop-out }\end{array}$ & $\begin{array}{c}\text { Terminated } \\
\text { participants }\end{array}$ \\
\cline { 2 - 4 } $\begin{array}{l}\text { Two-year rearrest } \\
\text { rate }\end{array}$ & $24.6 \%$ & $76.9 \%$ & $90.7 \%$ \\
$\begin{array}{l}\text { Mean days in jail } \\
\text { postexit }\end{array}$ & 2.8 & 113.6 & 202.3
\end{tabular}

Rearrest rates for MHC participants 12 months preenrolment and 12 months

Herinckx et al. 2005 [56]

Clark County, Washington postenrolment: The results were statistically significant $(p<.001)$.

Pre-post comparison $\ddagger$

Rearrest rates one-year preenrolment

MHC

Rearrest rates one-year postenrolment

1.99

Rearrest rates for $\mathrm{MHC}$ completers, those ejected from $\mathrm{MHC}$ and those who opted out

Hiday \& Ray 2010 [57]

County in North Carolina of MHC over a two-year period. The results between completers and noncompleters were statistically significant $(p<.001)$.

Pre-post comparison§

MHC

Ejected from MHC

Opt-out

Rearrested rate

$28 \%$

$81 \%$

$63 \%$

preenrolment

Ray, 2014 [58]

County in North Carolina

Significantly reduced rearrest rate for $\mathrm{MHC}$ completers compared to noncompleters during a 0-9 year follow-up period. In total, noncompleters were almost twice as likely to repeat offend $(p<.001)$ during a two-year follow-up period.

Pre-post comparison§

\begin{tabular}{lcc} 
& MHC & Non \\
\cline { 2 - 3 } Rearrest rate & $39.6 \%$ & $74.5 \%$ \\
Rearrest rate for a violent felony & $31.6 \%$ & $68.4 \%$ \\
\hline
\end{tabular}

*Pre-post comparison design between MHC and TAU participants

†Pre-post comparison design between MHC completers, voluntary opt-outs, and terminated

†Pre-post comparison for MHC completers (no comparison group)

$\S$ Pre-post comparison between MHC completers and non-completers

participation in the MHC, compared to $74.8 \%$ for noncompleters. Finally, research [57] reported that $24.6 \%$ of MHC graduates reoffended twoyears postprogram, compared to $76.9 \%$ for optouts and $90.7 \%$ for expelled participants.

\section{Canadian studies}

Out of the five Canadian studies, only two [40,41] used a robust research design. Both used a quasi-experimental pre-post comparison design between MHC and TAU participants (as well as differentiating between MHC completers, nonstarters, and partial completers). Two other [40,41] studies used a pre-post design, and one [42] compared MHC participants in 2010 with TAU participants from 2005 (see Table 3 [40-44]).

Of the other three studies, one study [44] found that their MHC participants averaged fewer days spent in jail, and had fewer charges and convictions two years after program admission, compared to two-years preprogram admission. MHC participants averaged 6.4 days in custody in the two years before program admission but only 2.8 days in custody post admission. Second, Nguyen [43] compared the recidivism rates for $189 \mathrm{MHC}$ completers and noncompleters between 2011 and 2017 during three intervals: 
Table 3 Summary of Canadian MHC research that analyzes recidivism rates

Study

Campbell et al., 2015 [40]

Dartmouth, Nova Scotia

Quasi-experimental: prepost comparison design between $\mathrm{MHC}$ and TAU participants

Campbell et al., 2015 [41]

Saint John, New Brunswick

Quasi-experimental pre-post comparison design between MHC and TAU participants

Dias, 2015 [42] Kenora, Ontario

Quasi-experimental pre-post comparison design between MHC and TAU participants

Nguyen, 2018 [43]

Peterborough, Ontario

Quasi-experimental pre-post noncomparison design for completers and noncompleters

Findings

For MHC participants, neither the on-year rearrest rate $(p<.949)$ nor one-year arrest for violent offences $(p<.074)$ were statistically significant.

One-year rearrest rate

\begin{tabular}{cc} 
MHC & TAU \\
\hline $30.8 \%$ & $31.5 \%$ \\
$3.8 \%$ & $18.5 \%$
\end{tabular}

One-year rearrest for violent offence

Although completers had the lowest recidivism rate, these results were not statistically significant $(p<.074)$.

.67-month recidivism rate

\begin{tabular}{ccc} 
MHC & Nonstarter & Noncompleter \\
\hline $28.6 \%$ & $32.6 \%$ & $50.0 \%$
\end{tabular}

Percentage of MHC and TAU participants who were charged with a crime one-year postprogram admission. The results did not indicate if it is statistically significant.

Rearrest rate one-year follow-up

\begin{tabular}{cc} 
MHC & TAU \\
\hline $26 \%$ & $51 \%$
\end{tabular}

Rates of MHC completers and noncompleters charged with at least one offence at oneand two-year intervals. The results for MHC completers during a one-year follow-up period $(p<.001)$ was statistically significant but not for the second year $(p<.05)$

\begin{tabular}{lcc} 
& MHC & Noncompleter \\
\cline { 2 - 3 } One-year recidivism rate & $25 \%$ & $66 \%$ \\
Two-year recidivism rate & $23 \%$ & $46 \%$
\end{tabular}

Watts \& Weinrath, 2017 [44] The number of days spent in jail for MHC participants before and after program admission. Winnipeg, Manitoba The reductions in days spent in custody were statistically significant $(p<.001)$.

Pre-post design only $\mathrm{MHC}$ participants

Days in jail per month during a two-year period

\begin{tabular}{cc} 
PreMHC & PostMHC \\
\hline 6.4 & 2.8
\end{tabular}

1. while in the program,

2. during the first-year postprogram, and

3. during the second-year postprogram.

MHC completers had considerably lower recidivism rates. Another study [43] found that completers and those still in the program had similar recidivism rates, and that $\mathrm{MHC}$ completers were significantly less likely to reoffend during both the first- and second-year postprogram. Only $25 \%$ and $23 \%$ of MHC completers reoffended during the first- and second-years post program, respectively, compared to $66 \%$ and $46 \%$ for noncompleters, respecitvely.
Drawing from the two MHC-TAU-group studies, Campbell et al. [40] compared the recidivism rates 12-months pre-post admission for:

1. completers;

2. still active participants;

3. partial completers who were expelled from the program because of noncompliance;

4. partial completers who voluntarily withdrew from the program; and

5. participants who were referred to the $\mathrm{MHC}$, but who were then referred to regular docket court (TAU). 
Campbell et al. [40] reported that recidivism rates between MHC and TAU participants were not significantly different. Completers, partial completers, voluntary withdrawal, and TAU participants all had similar reoffending rates. However, completers had the lowest recidivism rates, and those who were expelled from the program had considerably higher, statistically significant recidivism rates across all categories.

In another report, Campbell et al. [41] compared the recidivism rates for $\mathrm{MHC}$ program completers, partial completers who either withdrew from the program or were dismissed, and those who were referred to the MHC program but were ultimately referred to the traditional courts (TAU). That report found completers had the lowest recidivism rates $(28.6 \%)$, followed by TAU participants (32.6\%) and partial completers (50\%) [41].

Dias [42] compared the recidivism rates for one year for individuals involved with $\mathrm{MHC}$ in 2010 (experimental) and individuals involved with regular court in 2005. That report found $51 \%$ of participants in the regular court reoffended, whereas only $26 \%$ of MHC participants reoffended.

\section{Discussion}

MHCs have proliferated across Canada and the United States in the past two decades. Although there has been a growing literature in the United States, including several meta-analyzes, there is a lack of Canadian research analyzing recidivism rates and on the day-to-day operations of MHCs. This study adds to the literature by highlighting the number and locations of Canadian MHCs (see Table 1) and everyday MHC practices. We recommend other scholars and criminal justice practitioners to conduct additional studies on Canadian MHCs. At the qualitative level, the goals and day-to-day operations of MHCs vary widely, particularly in Canada. There is a lack of standardized guidelines for Canadian MHCs. The stated goals of Canadian MHCs were unevenly distributed between diverting those with mental illnesses away from the justice system, improving health outcomes, and reducing recidivism.
Therefore, we recommend standardized criteria for Canadian MHCs to follow.

Canadian and American MHCs are similar. Both use eligibility and screening measures. However, American MHCs use more robust screening measures (e.g., three stages) and typically admit more participants with the big three diagnoses. Moreover, American MHCs typically have several individuals involved in screening measured compared to the typical Canadian practice of having one or two individuals involved. Canadian and American MHCs use similar sanctions and rewards. Canadian and American courts provide a withdrawal, staying, or reduction of charges after participants successfully complete the program. Both courts sanction participants for not following court-mandated conditions.

At the quantitative level, the American literature included considerably more robust research methodologies, with 11 of the studies employing either an experimental or a quasi-experimental pre-post comparison design. Of those 11 studies, MHC completers had the lowest recidivism rates, followed by TAU, and then noncompleters. Only two Canadian studies $[40,41]$ used a quasiexperimental and control group design, with three studies comparing pre-post rates between MHC completers and noncompleters. Both comparison studies reported lower (although not statistically significant) recidivism rates among MHC participants while the non MHC-TAU studies reported that completers had lower recidivism rates than noncompleters.

\section{Conclusion}

We recommend scholars work with Canadian MHCs to compare recidivism rates for $\mathrm{MHC}$ and TAU participants. Future research should include rigorous multiple-year studies analyzing rearrest rates (and compare the commission of serious crimes between the groups), reconviction rates, and days spent in prison for MHC participants who successfully complete the program, those who were terminated from the program, and those who either chose to or were streamlined into the regular justice stream [57]. 
MHC research should inform public policy. Most of the research on MHCs indicates participants who successfully completed the program had lower recidivism rates across several measures. At the same time, however, this same research also indicated that those who were expelled from the MHC because of noncompliance also had increased recidivism rates compared to all other participants, including those who were referred to regular docket court. Future research should examine why MHCs reduce recidivism, to discover the predictors for increased recidivism for MHC noncompleters, and to discover risks and protective factors in this population.

Conflict of Interest: none

\section{References}

1. Slinger E, Roesch R. Problem-solving courts in Canada: a review and a call for empirically-based evaluation methods. Int J Law Psychiatry. 2010;33(4):258-64.

2. Watson A, Hanrahan P, Luchins D, Lurigio A. Mental health courts and the complex issue of mentally ill offenders. Psychiat Serv. 2001;52(4):477-81.

3. Wright, ER, Gronfein WP, Owens TJ. Deinstitutionalization, social rejection, and the selfesteem of former mental patients. J Health Soc Behav. 2000;68-90.

4. James DJ, Glaze LE. Mental health problems of prison and jail inmates. Washington, DC: U.S. Department of Justice. 2006:1-12. (accessed on May 14, 2020).

5. Office of the Correctional Investigator. Annual report of the Office of the Correctional Investigator 2011-2012. Ottawa: OCI. (accessed on May 14, 2020).

6. Snedker KA. Therapeutic justice: crime, treatment courts and mental illness. Springer; 2018.

7. Winick BJ. Therapeutic jurisprudence and problem solving courts. Fordham Urb LJ. 2002;30:1055-104.

8. Erickson S, Campbell A, Lamberti J. Variations in mental health courts: Challenges, opportunities, and a call for caution. Community Ment Health J. 2006;42(4): 335-44.

9. Kaiser H. Too Good to be true: Second thoughts on the proliferation of mental health courts. Can J Community Health. 2010; 29(2):19-25.

10. Sarteschi C, Vaughn M., Kim K. Assessing the effectiveness of mental health courts: A quantitative review. J Crim Justice. 2011;39(1):12-20.
11. Sarteschi CM, Vaughn MG. Recent developments in mental health courts: What have we learned? J Forensic Soc Work. 2013;3(1):34-55.

12. Honegger LN. Does the evidence support the case for mental health courts? A review of the literature. Law Hum Behav. 2015;39(5):478-88.

13. Lowder EM, Rade CB, Desmarais SL. Effectiveness of mental health courts in reducing recidivism: a metaanalysis. Psychiat Serv. 2017;69(1):15-22.

14. Canada K, Barrenger S, Ray B. Bridging mental health and criminal justice systems: A systematic review of the impact of mental health courts on individuals and communities. Psychol Public Policy Law. 2019;25(2):73.

15. Mauer M. Americans behind bars: a comparison of international rates of incarceration. Washington (DC): Sentencing Project: 1991. (accessed on May 14, 2020).

16. Fulmer JL. A brief report on the direct and indirect cost of prison incarceration in the state of Alabama. $J$ Correctional Education. 1995;46(1):16-8.

17. Caulkins JP, Rydell CP, Schwabe WL, Chiesa J. Mandatory minimum drug sentences: throwing away the key or the taxpayers' money? Washington (DC):Rand, 1997. (accessed on May 14, 2020).

18. Wexler DB, Winick BJ. Essays in therapeutic jurisprudence. Carolina Academic Press; 1991.

19. Daicoff S. The Role of Therapeutic Jurisprudence within the Comprehensive Law Movement. In: Stolle DP, Wexler BJ, Winick BJ (eds). Practicing Therapeutic Jurisprudence: Law as a Helping Profession. Durham: Carolina Academic Press; 2000.

20. Hora PF, Schma WG, Rosenthal JT. Therapeutic jurisprudence and the drug treatment court movement: Revolutionizing the criminal justice system's response to drug abuse and crime in America. Notre Dame $L$ Rev. 1998;74:439-537.

21. Council of State Governments, Justice Center. Mental Health Courts. 2019. (accessed on May 14, 2020).

22. Castellano U, Anderson L. Mental health courts in America: Promise and challenges. Am Behav Sci. 2013;57(2):163-73.

23. Steadman HJ, Redlich AD. Final report: An evaluation of the Bureau of Justice Assistance Mental Health Court Initiative. Washington, DC: National Institute of Justice (NIJ); 2006. (accessed on May 14, 2020).

24. Thompson M, Osher F, Tomasini-Joshi D. Improving response to people with mental illnesses: the essential elements of a mental health court. Counsel 
of State Governments, Criminal Justice/Mental Health Consensus Project; 2007. (accessed on May 14, 2020).

25. Wolff N, Fabrikant N, Belenko S. Mental health courts and their selection processes: Modeling variation for consistency. Law Hum Behav. 2011;35(5):402-12.

26. Redlich AD, Hoover S, Summers, A, Steadman HJ. Enrollment in Mental Health Courts: voluntariness, knowingness, and adjudicative competence. Law Hum Behav. 2010;34(2):91-104

27. Sarteschi C, Vaughn M, Kim K. Assessing the effectiveness of mental health courts: A quantitative review. J Crim Justice. 2011;39(1):12-20.

28. McNeil D, Binder R. Effectiveness of a mental health court in reducing recidivism and violence. $A m \mathrm{~J}$ Psychiatry. 2007;164(9):1395-403.

29. Steadman HJ, Redlich AD, Griffin P, Petrila J, Monahan J. From referral to disposition: case processing in seven mental health courts. Behav Sci Law. 2005;23(2):215-26.

30. Luskin, ML. Who is diverted? Case selection for courtmonitored mental health treatment. Law \& Policy. 2002;23(2):217-36.

31. Burns P, Hiday V, Ray B. Effectiveness 2 years postexist of a recently established mental health court. Am Behav Sci. 2013;57(2):189-208.

32. Trupin E, Richards H. Seattle's mental health courts: Early indicators of effectiveness. Int J Law Psychiatry. 2003;26(1):33-53.

33. Steadman HJ, Redlich A, Callahan L, Robbins PC, Vesselinov R. Effects of mental health courts on arrests and jail days: a multisite study. Arch Gen Psychiatry. 2011;68(2):167-72.

34. Cosden M, Ellens J, Schnell J, Yamini-Diouf Y. Efficacy of a mental health treatment court with assertive community treatment. Behav Sci Law. 2005;23(2):199-214.

35. Snedker KA, Beach LR, Corcoran KE. Beyond the "revolving door?: Incentives and criminal recidivism in a mental health court. Crim Justice Behav. 2017;44(9):1141-62.

36. Redlich AD, Steadman HJ, Robbins PC, Swanson JW. Use of the criminal justice system to leverage mental health treatment: effects on treatment adherence and satisfaction. J Am Acad Psychiatry Law. 2006;34(3):292-9.

37. Callahan L, Steadman HJ, Tillman S, Vesselinov R. A multi-site study of the use of sanctions and incentives in mental health courts. Law Hum Behav. 2013;37(1):1-9.
38. Mental health courts in Ontario: a review of the initiation and operation of mental health courts across the province. Ontario: Provincial Human Services and Justice Coordinating Committee and Canadian Mental Health Association, Ontario (accessed on May 14, 2020).

39. Cardwell M. Mental Health Courts on the rise in Quebec. Canadian Lawyer: 2018. (accessed on May 14, 2020).

40. Campbell MA, Adams N, Ennis A, Canales D. Prospective evaluation of the Nova Scotia Mental Health Court: an examination of short term outcomes. Saint John (NB): Centre for Criminal Justice Studies: 2015. (accessed on May 14, 2020).

41. Campbell MA, Canales DD, Wei R, Totten AE, Macauley WAC, Wershler JL. Multidimensional evaluation of a mental health court: adherence to the risk-need-responsivity model. Law Hum Behav. 2015;39(5):489-502.

42. Dias S. Does participation in mental health court reduce recidivism? A thesis submitted to the University of Manitoba: 2014. (accessed on May 14, 2020).

43. Nguyen N. Peterborough community support court: an evaluation of recidivism. Unpublished MA thesis. Trent University: 2018. (accessed on May 14, 2020).

44. Watts J, Weinrath M. The Winnipeg mental health court: preliminary findings on program implementation and criminal justice outcomes. Can J Community Mental Health. 2017;36(1):67-82.

45. Anestis JC, Carbonell JL. Stopping the revolving door: effectiveness of mental health court in reducing recidivism by mentally ill offenders. Psychiat Serv. 2014;65(9):1105-12.

46. Christy A, Poythress N, Boothroyd R, Petrilla J. Evaluating the efficiency and community safety goals of the Broward County Mental Health Court. Behav Sci Law. 2005:23(2):227-43.

47. Frailing K. How mental health courts function: outcomes and observations. Int $J$ Law Psychiatry. 2010;33(4):207-13.

48. Han W, Redlich AD. The impact of community treatment on recidivism among mental health court participants. Psychiat Services. 2016;67(4):384-90.

49. Hiday VA, Ray B, Wales HW. Longer-term impacts of mental health courts: recidivism two years after exit. Psychiat Services. 2016:67(4):378-83. (accessed on May 14, 2020).

50. Hiday VA, Wales HW, Ray B. Effectiveness of a shortterm mental health court: criminal recidivism one year postexit. Law Hum Behav. 2013;37(6):401-11. 
51. Keator K, Callahan L, Steadman H, Vesselinov. The impact of treatment on the public safety outcomes of mental health court participants. Am Behav Sci. 2013;57(2):231-43.

52. Kubiak S, Roddy J, Comartin E, Tillander E. Cost analysis of long-term outcomes of an urban mental health court. Eval Program Plann. 2015;52:96-106.

53. Lowder EM, Desmarais SL, Baucom DJ. Recidivism following mental health court exit: between and within-group comparisons. Law Hum Behav. 2016;40(2):118-27.

54. McNiel DE, Sadeh N, Delucchi KL. Prospective study of violence risk reduction by a mental health court. Psychiatric Services. 2015;66(6):598-603.

55. Moore ME, Hiday VA. Mental health court outcomes: a comparison of re-arrest severity between mental health court and traditional court participants. Law Hum Behav. 2006;30(6):659-74.
56. Herinckx HA, Swart SC, Ama SM. Rearrest and linkage to mental health services among clients of the Clark County mental health court program. Psychiat Serv. 2005;56(7):853-7.

57. Hiday VA, Ray B. Arrests two years after exiting a well-established mental health court. Psychiat Serv. 2010;61(5):463-8.

58. Ray B. Long-term recidivism of mental health court defendants. Int J Law Psychiatry. 2014;37(5):448-54.

\section{Corresponding Author:}

David Tyler Dunford, University of Alberta, 116 St. \& 85 Ave., Edmonton, AB T6G 2R3, Canada - email: tdunford@ ualberta.ca 